www.jmscr.igmpublication.org

Impact Factor 5.244

Index Copernicus Value: 5.88

ISSN (e)-2347-176x ISSN (p) 2455-0450

crossref DOI:_http://dx.doi.org/10.18535/jmscr/v4i3.23

Journal Of Medical Science And Clinical Research

IGM Publication

An Official Publication of IGM Publication

\title{
The Comparative Study of Homocysteine, Folate and Cobalamine Level in Hyperthyroid Women and Normal Healthy Women
}

\author{
Authors \\ Choudhary Nitu ${ }^{1}$, Kumar Rohitash ${ }^{2}$, Dr Vyas R. K. ${ }^{3}$ \\ ${ }^{1}$ M.Sc (Medicine) Biochemistry, S.P. Medical College, Bikaner, India \\ ${ }^{2}$ M.Sc (Medicine) Biochemistry, Senior Demonstrator, Dept of Biochemistry, SMS Medical college, India \\ ${ }^{3}$ M. Sc (Medicine)/ PhD Biochemistry, Professor \& Head, Department of Biochemistry, S.P. Medical \\ College, Bikaner India \\ Corresponding Author \\ Rohitash Kumar \\ M.Sc. (Medicine) Biochemistry, Senior Demonstrator, Department of Biochemistry, \\ SMS Medical College, Jaipur, Rajasthan (INDIA) \\ Email: simply.rohitbhariya@gmail.com, Mob: - 09602695338
}

\begin{abstract}
Background: Thyroid disorders are among the most common endocrine disorders in India. The prevalence and pattern of the thyroid disorders depends on age, sex, geographical factors, food habits and on iodine intake. ${ }^{(1)}$ A Hospital based case-control study was planned, including 50 patients of clinically proven hyperthyroid disease women patient (Case) and 50 age and sex matched controls attending medicine OPD and microbiology department of S. P. Medical College and Associated Group of Hospitals, Bikaner for study of Homocysteine, Folate and Cobalamine levels.

Method: Plasma Homocysteine, Folate and Cobalamine levels were measured by HPLC (High Performance Liquid Chromatography) Method in clinical Biochemistry laboratory, S. P. Medical College, Bikaner.

Results: A statically significant decreased concentration of plasma homocysteine was recorded in hyperthyroid patients as compared to Controls (p-value 0.0001). The serum vitamin B9 (folic acid) concentration was found to be decreased significantly in hyperthyroid female patients as compared to Controls (p-value 0.0001). A statically significantly increased concentration of serum cobalamine (Vit $B_{12}$ ) was found in hyperthyroid patients as compared to normal control female subject ( $p$-value 0.0001).

Conclusion: Estimation of Serum Homocysteine, Folate and Cobalamine level is simple, reliable, economic and sensitive and it can be used in the proper management of developing new therapeutic strategies in treatment of hyperthyroid women patients.

Keywords: Homocysteine, Folate, Cobalamine, Hyperthyroidism.
\end{abstract}




\section{Introduction}

Hyperthyroidism, often referred to as an overactive thyroid, is a condition in which the thyroid gland produces and secretes excessive amounts of the free (not protein bound, and circulating in the blood) thyroid hormones, tri iodothyronine $\left(\mathrm{T}_{3}\right)$ and thyroxine $\left(\mathrm{T}_{4}\right)^{2}$. This is the opposite of hypothyroidism (sluggish thyroid), which is the reduced production and secretion of T3 and T4. ${ }^{(3)}$ Grave's disease is the most common cause of hyperthyroidism. ${ }^{(4)}$

Hyperthyroidism is one cause of thyrotoxicosis, the hypermetabolic clinical syndrome which occurs when there are elevated serum levels of T3 and T4. ${ }^{(5)}$ Thyrotoxicosis can also occur without hyperthyroidism. Some people develop thyrotoxicosis due to inflammation of the thyroid gland (thyroiditis), which can lead to excessive release of thyroid hormone already stored in the gland (without the accelerated hormone production that characterizes hyperthyroidism).

Patients may present with a variety of physical symptoms such as palpitation and arrhythmias (the notable ones being atrial fibrillation), shortness of breath (dyspnea), loss of libido, amenorrhoea, nausea, vomiting, diarrhrea, gynaec omastia and feminization. ${ }^{(6)}$ Long term untreated hyperthyroidism can lead to osteoporosis. These classical symptoms may not be present often in the elderly.

In Grave's disease, which is the most common form or cause of hyperthyroidism, the eyes may look enlarged because the eye muscles swell and push the eye forward. This can only be resolved surgically by orbital decompression. Sometimes, one or both eyes may bulge. Some patients have swelling of the front of the neck from an enlarged thyroid gland (a goiter). Because hyperthyroidism, especially Grave's disease, may run in families, examinations of the members of a family may reveal other individuals with thyroid problems. ${ }^{(7)}$

\section{Material \& Methods}

The present study will comprise of 100 female subjects for study. 50 age and sex matched controls and 50 hyperthyroid women patients were included in study, attending clinical microbiology laboratory and medicine OPD, S.P. Medical College and Associted Group of Hospitals. Following investigation were performed in all the subjects included in this study in clinical Biochemistry laboratories, Department of Biochemistry, of S. P. Medical College and Hospital, Bikaner (Rajasthan):

1. Serum Homocysteine level were measured by HPLC Method (High Performance Liquid Chromatography) method. The reagents are ready to use and serum was analyzed on HPLC analyser.

2. Serum Folate level were measured by HPLC Method (High Performance Liquid Chromatography) method. The reagents are ready to use and serum was analyzed on HPLC analyser.

3. Serum Cobalamine level were measured by HPLC Method (High Performance Liquid Chromatography) method. The reagents are ready to use and serum was analyzed on HPLC analyser.

\section{Results}

Risk of developing Hyperthyroidism, was assessed by evaluating Homocysteine, Folate and Cobalamine levels in 50 consecutive patients (50 females) diagnosed clinically to have Hyperthyroidism and fulfilling the predetermined inclusion criteria. 50 age and sex matched Healthy women (50 females) served as controls.

The mean values of serum Homocycteine, Folate and cobalamine in Cases and Control were $(11.15 \pm 1.82 \mathrm{v} / \mathrm{s} \quad 2.50 \pm 0.90), \quad(5.57 \pm 1.55 \mathrm{v} / \mathrm{s}$ $9.73 \pm 2.42), \quad(276.08 \pm 120.01 \mathrm{v} / \mathrm{s} \quad 341.50 \pm 25.58)$ $\mu \mathrm{mol} / \mathrm{L}$ respectively, the difference being highly significant ( $\mathrm{p}=0.0001)$. (Table No. 1, 2, 3).

A statistically significant $(\mathrm{p}=0.0001)$ decreased concentration of serum folic acid was observed in hyperthyroid women as compared to the normal control women with same age differences in our study (table 01). 
Table: 01. Mean Serum folate Concentration $(\mu \mathrm{mol} / \mathrm{L})$ in Hyperthyroid patients with that of Control

\begin{tabular}{|c|c|c|c|}
\hline S.NO & Values & Control Group & Hyperthyroid group \\
\hline 1 & Mean & 5.57 & 9.73 \\
\hline 2 & Range & $3.14-9.2$ & $6.4-15.91$ \\
\hline 3 & SD & 1.55 & 2.42 \\
\hline 4 & SE & 0.22 & 0.343 \\
\hline 5 & DF & 98 & \\
\hline 6 & T & 10.188 & \\
\hline 7 & P-value & 0.0001 & \\
\hline
\end{tabular}

A statistically significant $(\mathrm{p}=0.0001)$ decreased concentration of serum Homocyctein was observed in hyperthyroid women as compared to the normal control women with same age differences in our study (table 02).

Table: - 02. Mean Serum Homocystein Concentration $(\mu \mathrm{mol} / \mathrm{L})$ in Hyperthyroid patients with that of Control

\begin{tabular}{|c|c|c|c|}
\hline S.NO & Values & Control Group & Hyperthyroid group \\
\hline 1 & Mean & 11.15 & 2.501 \\
\hline 2 & Range & $6.8-13.87$ & $0.97-4.12$ \\
\hline 3 & SD & 1.82 & 0.903 \\
\hline 4 & SE & 0.257 & 0.127 \\
\hline 5 & DF & 98 & \\
\hline 6 & T & 30.08 & \\
\hline 7 & P-value & 0.0001 & \\
\hline
\end{tabular}

A statistically significant $(\mathrm{p}=0.0001)$ increased concentration of serum Cobalamine was observed in hyperthyroid women as compared to the normal control women with same age differences in our study (table 03).

Table:-03. Mean Serum Cobalamine $(\mu \mathrm{mol} / \mathrm{L})$ in Hyperthyroid patients with that of control

\begin{tabular}{|c|c|c|c|}
\hline S.NO & Values & Control Group & Hyperthyroid group \\
\hline 1 & Mean & 276.08 & 341.50 \\
\hline 2 & Range & $136.0-468.0$ & $300.0-396.0$ \\
\hline 3 & SD & 120.01 & 25.58 \\
\hline 4 & SE & 16.97 & 3.61 \\
\hline 5 & DF & 98 & \\
\hline 6 & T & 3.769 & \\
\hline 7 & P-value & 0.0001 & \\
\hline
\end{tabular}

\section{Discussion \& Conclusion}

Anna Orzechowska- Pawilojc A, Siekierska Hellmann $\mathrm{M}$ et al. ${ }^{(8)}$ also found that the serum level of folate was low in hyperthyroid women as compared to the normal control women.

Gyftaki H, Kesse- Elias et al ${ }^{(9)}$ observed that mean serum folic acid levels were higher in the hyperthyroid patients than in normal controls but the difference was not statistically significant $(\mathrm{t}=$ 1.2, $\mathrm{P}$ greater than 0.2 ).
A statistically significant $(\mathrm{p}=0.0001)$ decreased concentration of serum folic acid was observed in hyperthyroid women as compared to the normal control women with same age differences in our study.

Dermirbas B et al (10) study of homocysteine levels of the hyperthyroid patients were significantly lower than healthy controls $(11.5+/-$ $3.6 \mathrm{micromol} / \mathrm{L}$ vs. $15.1+/-4.5 \mathrm{micromol} / \mathrm{L}$, respectively, $\mathrm{P}<0.005)$. 
A Lien et al ${ }^{(11)}$ study of homocysteine (tHcy) in plasma and that homocysteine is reduced in hyperthyroid state as compared with the normal subjects.

A statistically significant $(\mathrm{p}=0.0001)$ decreased concentration of serum Homocyctein was observed in hyperthyroid women as compared to the normal control women with same age differences in our study.

Gyftaki H et al ${ }^{(12)}$ conducted A study of serum vitamin B12 level, which was lower in hyperthycoid patients than in normal controls, the difference being statistically significant $(\mathrm{t}=2.584$, $P$ less than 0.025).

Nedrebo BG et al ${ }^{(13)}$ study shows that the serum cobalamin level was low and serum folate level was higher in hyperthyroid patients.

Bjorn G. Nedrebo et al ${ }^{(14)}$ found in their study that hyperthyroid patients serum cobalamine level have no significant change as compare with controls.

A statistically significant $(p=0.0001)$ increased concentration of serum Cobalamine was observed in hyperthyroid women as compared to the normal control women with same age differences in our study

After this study, we can conclude evidently that hyperthyroidism is a predominantly a hormonal disorder. As per above discussion we found a significant correlation of hyperthyroidism with Serum Homocysteine, Folate and Cobalamine levels.

This study is a pioneer in evaluation of Serum Homocysteine, Folate and Cobalamine levels in hyperthyrois women patients in Rajasthan.

Hence, this study has been a step forward to find relation of Serum Homocysteine, Folate and Cobalamine levels with hyperthyroid and raises a fundamental issue of need of further research in this direction which can help in better understanding of this disease and in developing new therapeutic strategies in treatment of hyperthyroid women patients.

\section{References}

1. Nimmy N.J, Annesh P.M. et al "A survey on the prevalence of thyroid disorder induced by demography and food habits in south. India population" 2012.

2. Dario M. Torre, Geoffrey C. Lamb, Jerome Van Ruiswyk: Kochar's Clinical Medicine for Students. pp.402-403: Lippincott Williams \& Wilkins; Fifth edition (2008) ISBN 0-7817-6699-0

3. "Floyd, J.L. (2009) Thyrotoxicosis. eMedicine"

4. Heineke J.W.Rosen., H.Suzuki L.A. and Chait A.role of sulfur containing amino acid in superoxide production and modification of LDL.J.Bio.chem.(1987) 262:10098-10103.

5. Mccully K.S. and Carvaloh, A.C Homocystiene,thiolactone homocystiene thiolactonyl retinamide and platelet aggregation-Res.communi. chem. Pathopharmacolgy(1987) 56:349: 360.

6. "Depression and Psychosis in Neurological Practice.".Bradley's neurology in clinical practice. (6th ed.). Philadelphia, PA: Elsevier/Saunders. 2012. p. 102-103 Chan WB, Yeung VT, Chow CC, So WY, Cockram CS. (1999). "Gynaecomastia as a presenting feature of thyrotoxicosis". Postgrad Med J. 882 (75): 229-31. PMC 1741202. PMID 10715765.

7. Janet E. Hall, Lynnette K. Nieman: Handbook of diagnostic endocrinology, pp. 124-125

8. Anna Orzechowska- Pawilojc, Krzysztof Sworczak et al "Homocysteine, folate and cobalamin levels in hyperthyroid women before and after treatment 2007; 54(3): 471-6.

9. Gyftaki H, Kesse-Elias $M$ et al "Serum vitamin B12 and folic acid levels in hyperthyroidism' 'Nuklearmedizin. 1979; 18 (6):278-82.

10. Dermirbas B, Ozkaya M et al "Plasma homocysteine levels in hyperthyroid 
patients" Endour J 2004 Feb; 51 (1): 121125.

11. Lien EA, Aakvaag A et al" Plasma total homocysteine levels during short terms iatrogenic hypothyroidism." 2000; 85:1049-1053.

12. Gyftaki H, Kesse-Elias $M$ et al "Serum vitamin B12 and folic acid levels in hyperthyroidism' 'Nuklearmedizin. 1979; 18 (6):278-82.

13. Nedrebo BG, Ericsson UB et al "Plasma total homocysteine levels in hyperthyroid Andhypothyroid patients' 'Metabolism. 19 98 Jan; 47(1):89-93.

14. Bjorn G.Nedrebo ,Ottar Nvgard et al "Plasma total Homocysteine in hyperthyroid and hypothyroid patients before and during 12 months of Treatment'"2001. 